\title{
Pain-related health care costs for long-term care residents
}

\author{
Harminder Guliani ${ }^{1}$, Thomas Hadjistavropoulos ${ }^{2^{*}}$, Shan Jin $^{3}$ and Lisa M. Lix
}

\begin{abstract}
Background: We tested for differences in direct health care costs among long-term care (LTC) residents age 65 and older with clinically significant pain (CSP) and with no pain or non-daily mild pain (NP/NDMP). We are not aware of any other large scale investigation that examined the cost of pain in LTC environments.

Methods: Population-based administrative health data from Saskatchewan, Canada for 2004 to 2015 were used to compare direct health care costs for CSP and NP/NDMP groups up to one year after admission to LTC. Total accumulated costs for hospitalization, physician services, LTC, and prescription drugs were calculated in 2015 Canadian dollars. Group differences were tested using generalized linear models with generalized estimating equations.
\end{abstract}

Results: Amongst 24,870 LTC residents, 8289 (33.3\%) were censored due to death or discharge in the 365-day study observation period. Of the 16,581 (66.7\%) observed residents, 5683 (34.3\%) had CSP at admission. Residents (66.3\% female) had a mean age of 85 years $(S D=7.4)$. The mean annual total direct health care cost per resident was higher among the CSP group (CAD \$8063) than the NP/NDMP group (CAD \$6455). This difference was found even after including LTC costs, and for each cost component (i.e., CSP residents had higher hospitalization, physician, and prescription drug costs). Similar results were obtained after controlling for demographics, comorbidities, physical and cognitive impairment, prior health care costs, and facility characteristics.

Conclusion: The higher costs incurred by CSP residents compared to NP/NDMP residents are likely underestimated because pain problems are often missed in residents with dementia, who comprise a large portion of the LTC population. Improved pain care can reduce such costs and improve quality of life.

Keywords: Direct health care cost, Nursing home, Clinically significant pain, Older adults, Canada

\section{Introduction}

Prevalence estimates for pain in residents of long-term care (LTC) facilities range from 40 to $85 \%$ depending on study methods and the population under investigation [1]. Despite this high prevalence, pain is often undertreated among LTC residents, many of whom have cognitive impairments $[1,2]$. People with cognitive impairments, for example, are less likely to receive analgesics than their cognitively intact counterparts [3, 4].

\footnotetext{
* Correspondence: Thomas.Hadjistavropoulos@uregina.ca

${ }^{2}$ Department of Psychology and Centre on Aging and Health, University of Regina, 3737 Wascana Pkwy, Regina, SK S4S 0A2, Canada

Full list of author information is available at the end of the article
}

This occurs, at least in part, because of limitations in ability to communicate subjective states such as pain due to cognitive decline [5] which affects a large portion of LTC residents. There is a paucity of research on the cost implications of pain in LTC environments.

Although pain care in LTC can be improved with increased assessment focusing on well validated observational methods that focus on pain behaviours [6, 7], resource constraints are often cited as barriers to improving care and to conducting frequent pain assessments [8]. It is difficult to fully address resource constraints without having a full understanding of health care costs incurred for residents with clinically

(c) The Author(s). 2021 Open Access This article is licensed under a Creative Commons Attribution 4.0 International License which permits use, sharing, adaptation, distribution and reproduction in any medium or format, as long as you give appropriate credit to the original author(s) and the source, provide a link to the Creative Commons licence, and indicate if changes were made. The images or other third party material in this article are included in the article's Creative Commons licence, unless indicated otherwise in a credit line to the material. If material is not included in the article's Creative Commons licence and your intended use is not permitted by statutory regulation or exceeds the permitted use, you will need to obtain permission directly from the copyright holder. To view a copy of this licence, visit http://creativecommons.org/licenses/by/4.0/ The Creative Commons Public Domain Dedication waiver (http://creativecommons.org/publicdomain/zero/1.0/) applies to the data made available in this article, unless otherwise stated in a credit line to the data. 
significant pain (CSP) as compared to those with no pain or with non-daily mild pain (NP/NDMP). If those who suffer from CSP incurred higher costs, the policy change for improved pain care would seem more feasible.

Researchers from several parts of the world have examined the cost of pain. In Canada, the direct care costs of pain have been estimated at CAD $\$ 6$ billion per year $[9,10]$. Those on waiting lists for access to pain clinics have been estimated to spend a median of CAD $\$ 17,544$ for various expenses related to funding private treatments and lost productivity [11]. Using a large, population-based sample of adolescents and adults, Hogan et al. [12] found that the annual incremental per-person cost to manage chronic pain in Ontario, Canada was CAD \$1742, which is $51 \%$ higher than health care costs for patients without chronic pain. These researchers also reported that health care costs were highest in patients reporting more severe pain and more activity limitations [12]. Similarly, Lalonde et al., [13] estimated the economic burden of chronic noncancer pain in primary care patients in the province of Quebec, Canada. They found that the total direct health care costs averaged CAD \$ 9565 per patient per year and varied positively with the level of pain disability. The mean adjusted total direct health care costs averaged CAD \$7374, CAD $\$ 10,524$, and CAD $\$ 9546$ for patients with mild, moderate, and severe pain disability, respectively [13].

In the United States, the incremental health care costs due to pain have been estimated as ranging between US $\$ 261$ billion and $\$ 300$ billion annually [14]. In their study, Gaskin and Richard [14] indicated that their cost estimates represent underestimates of the actual cost of pain in the United States because they excluded certain populations including residents of LTC facilities. Other studies from Europe and Australia also suggest increasing health care costs with an increase in pain severity [15-17]. Collectively, these studies indicate that the economic burden of pain is substantial. While much has been written on the economic cost of pain among the general population in Canada and elsewhere, very little is known about the cost of pain in LTC residents.

In a recent longitudinal investigation examining the health care utilization of Canadian LTC residents as a function of pain status, Guliani et al. [18] concluded that those with CSP (as compared to residents who had NP/ NDMP) had a greater risk of hospitalization, specialist physician visit, follow-up general practitioner visit, and use of various medications falling under at least three classes after controlling for comorbidities and prior health care utilization. Although health care utilization may be correlated with cost, it is not equivalent to cost. For example, a patient may have five physician visits, but these visits may cost considerably less than one 24-h hospital stay.

This study was, therefore, aimed to extend the findings of Guliani et al. [18] by describing the health care costs of LTC residents with CSP (defined as daily pain or moderate to severe non-daily pain) and residents with NP/NDMP. We hypothesized that LTC residents with CSP would have higher average cost compared to residents with NP/NDMP. An understanding of differences in costs between these groups will help health policymakers design efficient strategies to reduce and manage pain in LTC facilities.

\section{Methods}

\section{Study design and cohort}

We used a one-year longitudinal cohort design. Our cohort included LTC residents with CSP and NP/NDMP. Specifically, the study cohort included all Saskatchewan LTC residents age 65 years and older, who were admitted to an LTC facility between January 1, 2004, and December 31, 2015, and had a minimum of 365 days of continuous health care coverage before their LTC admission date (i.e., index date). Residents from 165 LTC facilities, who were alive for at least 90 days after admission to LTC, were included. We followed cohort members from the date of LTC admission to 365 days after the index date, or until they were censored due to death or discharge from LTC, whichever came first. In total, there were 7179 cohort members excluded due to death or discharge within 90 days of admission, out of which $49 \%$ had pain. The excluded cohort members were comparable in baseline characteristics (e.g., 62\% female with a mean age of 85 and a mean CPS score of 2) to included residents. Additionally, residents were excluded if they had no baseline pain assessment, had no LTC admission assessment, were less than 65 years of age at index date, or had incomplete or inconsistent data. The details of the cohort inclusion and exclusion criteria are reported in Fig. 1.

\section{Data sources}

We used population-based administrative health data to track the cost of publicly funded health care services. These data have been described by Guliani et al. [18] and are available from the Saskatchewan Ministry of Health and eHealth Saskatchewan via the Saskatchewan Health Quality Council. With a population of approximately 1.1 million, [19] the Canadian province of Saskatchewan provides medically necessary care for all eligible residents, including outpatient physician visits, inpatient and outpatient hospital services, home care, LTC, and out-of-hospital prescription drugs.

Study data were from the Resident Assessment Instrument-Minimum Data Set (RAI-MDS) [20, 21], 


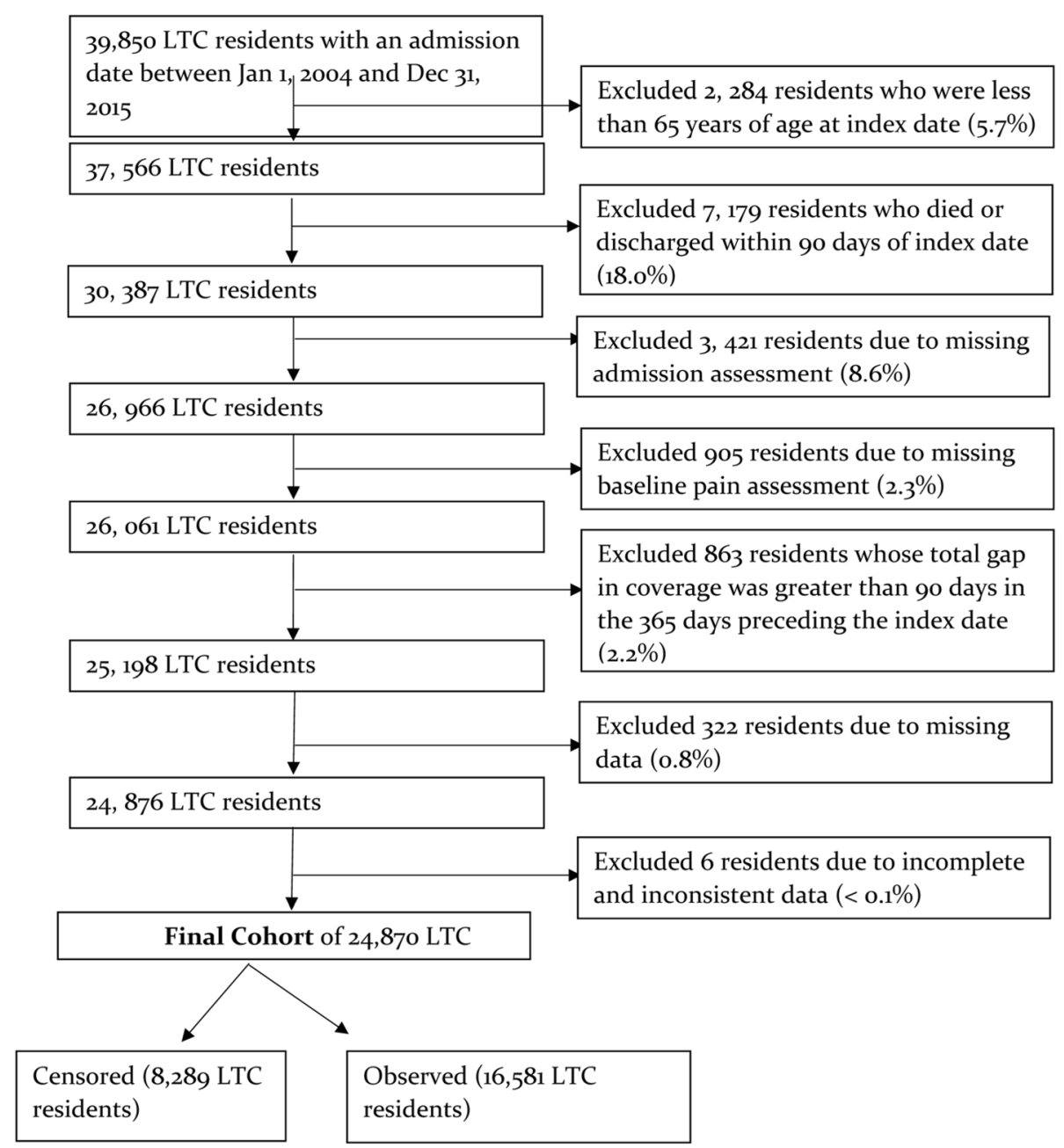

Fig. 1 Cohort selection flow chart [18]

which is a clinical assessment tool for LTC residents, Person Health Registry System (PHRS), Discharge Abstract Database (DAD), prescription drug file, physician claims database, and the provincial Institutional Supportive Care Home (ISCH) and Special Care Home System (SCHS) database. Residents' records from these databases were linked using unique personal health numbers and de-identified by replacing the personal health number with an unrelated study number. These Saskatchewan administrative health data cover nearly $99 \%$ of the province's residents. The data exclude those who receive federal government health benefits including federal prison inmates, members of the armed forces, and the Royal Canadian Mounted Police.

The RAI-MDS captures clinical information about care, functioning, and health status of LTC residents. This information is collected on admission, quarterly, and whenever there is a major change in a resident's health status $[20,21]$. The PHRS provides residents' health insurance coverage information, in addition to location of residence, and demographics.

The DAD provides information on all inpatient hospitalizations and day surgeries for patients of acute care facilities. Hospital abstracts are completed when a patient is discharged from an acute care facility, and diagnoses are recorded using the International Classification of Diseases, 10th revision, Canadian enhancement codes (ICD-10-CA) [22]. The physician claims database contains information on type and date of services, and a fee code that is used to determine the amount paid to the physician for each visit. A single diagnosis is recorded on each claim using a three-digit ICD-9 (i.e., 9th revision of ICD) code [23]. The adjudicated prescription drug database captures information on outpatient medications dispensed to people with provincial prescription coverage from September 1975 onward. However, prescription drug data were not consistently captured for LTC residents until 1996 because some LTC facilities received global funding for prescription drugs. That practice was 
discontinued by 1996. The prescription drug database excludes individuals who receive federal prescription coverage such as the military, federal police, federal prisoners, and Indigenous persons. Each available record includes the date of dispensation and a Health Canada drug identification number (DIN). The ISCH and SCHS database contains information on LTC facilities and length of stay for LTC residents. The ISCH database was decommissioned in 2013 and residents were migrated to the new Special Care Home System (SCHS) database in September 2013.

These databases have been used extensively for health services research in Saskatchewan $[18,24]$. Other researchers have found Saskatchewan's administrative health data to be reliable and complete [24, 25]. The study was approved by the Research Ethics Board, University of Regina. A standing data sharing agreement between the Saskatchewan Health Quality Council, the Ministry of Health, and eHealth Saskatchewan provided for access to the study data.

\section{Study variables \\ Health care costs}

Direct health care costs, expressed in Canadian dollars, were estimated for each LTC resident from the date of LTC admission until death, discharge, or the end of the 365-day study observation period. The total accumulated cost for each LTC resident was the sum of costs for hospitalization (both inpatient and outpatient [i.e., day surgery]), general and specialist physician services, LTC residence, and dispensed prescription drugs. All costs were adjusted for inflation using 2015 dollars and the Saskatchewan health care component of the Consumer Price Index (CPI) from the Canadian Socio-Economic Information Management System (CANSIM [26];). Costs were also cumulated for the 365-day period prior to LTC admission and were used to control for confounding in the statistical models.

We estimated the total cost using both micro-costing and macro-costing approaches [27, 28]. The microcosting approach, which combines appropriate unit costs with person-level utilization data (quantity $\mathrm{x}$ unit cost), was adopted to calculate the cost of physician services and prescription drugs. The macro-costing approach, commonly referred to as standard (or average) cost per service provided, was adopted to calculate the cost of inpatient hospitalizations, outpatient hospitalizations, and LTC stays.

The total hospital cost for each LTC resident was calculated by multiplying the cost of a standard hospital stay with its Resource Intensity Weight (RIW). The cost of a standard hospital stay for day surgery or inpatient hospital stay is the province-specific average direct cost per weighted case, which measures the province's average total cost of treating an average acute inpatient for a given fiscal year [29]. We used the same values for day surgeries and inpatient stays, which may have resulted in some overestimation of costs. Nonetheless, this should not be a major concern since day surgeries accounted for only $9 \%$ of the total number of hospitalization records in our data. The RIW measures the intensity of resource utilization associated with different diagnostic procedures, surgical procedures, and demographic characteristics of an individual [30]. RIWs are assigned according to Case-Mix Groups (CMG), a patient classification algorithm developed by the Canadian Institute for Health Information, a national not-forprofit organization that provides information on the Canadian health care system [31]. CMGs classify patients into homogeneous groups based on similar clinical and resource-utilization characteristics. It should be noted that our hospital cost estimates may underestimate the total cost of hospitalization as it excludes hospital operational and building capital costs (e.g., hospital administration, utilities, or other capital-related costs) as well as visits to ambulatory clinics such as emergency departments.

The cost of physician services for each LTC resident was calculated by summing the fees for all physician visits during the study period. These costs were calculated separately for general practitioners and specialist physicians. In the case of non-fee-for-service physician payments, shadow billing claims were used to compute physician costs using the equivalent fee-for-service value. Some non-fee-for-service physicians may not submit shadow-billed claims. However, existing research supports the validity and completeness of the physician claims data for capturing the vast majority of physician services [25, 32].

The prescription drug cost for each LTC resident was the total cost for all dispensed outpatient prescriptions; this included drug materials, dispensing fee, and markup. Costs for drugs used in acute care facilities are captured in the total hospital cost.

The cost of LTC services for each LTC resident was determined by multiplying the annual per-diem cost by the number of days a member of the study cohort was an LTC resident. The annual per diem cost was calculated by dividing the same value of annual LTC provincial expenditures for all facilities by the total number of resident days. This information was obtained from the Ministry of Health Community Care Branch.

\section{Covariates}

The primary covariate of interest was pain group, which had two categories: CSP and NP/NDMP. This measure was derived from RAI-MDS assessment records, which captures information on pain frequency (i.e., no pain, 
pain less than daily, daily pain) and its intensity (i.e., mild pain, moderate pain, pain is horrible or excruciating) at the index date and quarterly thereafter. The RAIMDS pain scale has been widely used for Canadian LTC residents [33] and its validity has been established [34]. Pain frequency and severity, stratified by sex is available in the Additional file accompanying this article. Similar to Guliani et al. [18], LTC residents with daily pain or less than daily pain that was of moderate or severe intensity were classified as having CSP. LTC residents with no pain or less than daily pain of mild intensity were classified as having NP/NDMP. Our approach to classification of patients in terms of their RAI-MDS pain status is consistent with quality indicator approaches used in Canada [35].

We also included the RAI-MDS Cognitive Impairment Scale (CPS [36]), Activities of Daily Living (ADL [36]), and Changes in Health, End-Stage Disease and Signs and Symptoms (CHESS [36]) as covariates in our regression analysis; these covariates measure residents' physical and cognitive impairment. The CPS evaluates the level of cognitive impairment affecting a patient such as memory, decision-making ability, communication skills and eating impairments, and is scored on a seven-point scale with a minimum value of zero and a maximum value of six. Higher scores indicate more severe cognitive impairment [36]. We used the ADL long-form scale to measure residents' self-sufficiency. The scale is composed of seven ADL items; total scale scores range from zero to 28 , with higher scores indicating less independence $[36,37]$. In our study, we categorized the ADL scores as $0-7,8-14,15-21$ and $22-28$. The CHESS scale is a measure of frailty and health stability designed to identify residents at risk of serious decline and takes on values from zero (no instability) to five (high instability). We have combined scores from three to five due to a small number of observations. A high CHESS score is shown to be a predictive of mortality in the LTC population [38]. Further details on these measures are provided by the Canadian Institute of Health Information [36].

Other covariates included residents' demographic characteristics at the index date (age, sex, rural/urban residence), comorbidities, prior direct health care costs for the 365-days before the index date, and LTC facility characteristics. Age was categorized as 65-74, 75-79, $80-84,85-89,90-94$, and $95+$ years. A resident's address from the PHRS at index date was used to classify the resident's location as rural or urban. An address from one of the two health regions containing major urban centers was classified as urban, while an address from one of the remaining 11 health regions was classified as rural.

The Charlson comorbidity index (CCI [39];) score was calculated for the 365-day period prior to the index date.
The index is based on ICD-9 and ICD-10-CA diagnosis codes captured in hospital and physician data [40, 41]. CCI scores were classified into four groups:, 0 (no comorbidities), 1, 2, and 3 or more comorbidities.

The natural $\log$ of total direct health care cost in the 365 -day period prior to the index date was included as a covariate. The total health care cost was the sum of hospitalization, general practitioner visits, specialist visits, and prescription drug cost. These costs were adjusted for inflation using 2015 dollars and CPI for Saskatchewan health care component of CANSIM.

The Saskatchewan ISCH database classifies LTC facilities as integrated, special care homes, and hospitalbased special care homes. Integrated LTC facilities provide the services of both an acute care facility and a special care home [42]. Special care homes are publicly funded and provide LTC services to qualified residents who require care and supervision that cannot be provided in their own homes [42]. Hospitalbased special care homes serve individuals who are still in a hospital but do not require acute care services. The facility type variable allows us to capture any unknown and unmeasured variations in the services that facilities provide.

\section{Statistical analysis}

Frequencies, percentages, means, standard deviations (SD), and the interquartile range (IQR) were used to describe the cost data. Descriptive statistics were stratified by pain group at baseline (i.e., index date).

Generalized linear models (GLMs) with generalized estimating equations (GEEs) were used to test for differences in the marginal total direct health care costs between the CSP and NP/NDMP groups before and after adjusting for other covariates (i.e., unadjusted and adjusted models). GLM models are widely used for modelling health care costs [43, 44]. GLM with GEEs allowed us to account for the repeated measurement of costs within patients over time and to make robust inferences by implicitly considering the correlation structure of the data. The assumption of a normal distribution for the outcome, which underlies ordinary least-squares regression, is violated for cost data because it has a skewed distribution. We initially analyzed the data using GLMs with gamma and inverse Gaussian distributions and used a likelihood-based goodness-offit statistic to assess which distribution provided the best fit for the data. Based on the assessment of model fit, we selected a gamma distribution and an identity link function.

Pain group was defined as a time-varying covariate; it was updated each time a resident's pain status changed based on information recorded during the RAI-MDS 
assessments. We used a time-varying covariate because pain status is unlikely to remain constant over time.

We first fit an unadjusted model to the cost data; it contained pain group, time, and the pain group $\mathrm{x}$ time two-way interaction. The two-way interaction enabled us to test whether the association of pain group with cost varied over time. We then fit a fully adjusted model that incorporated all patient and facility characteristics in addition to pain group, time, and the pain group $x$ time two-way interaction.

Two adjusted and unadjusted models were fit to the data: In Model 1, the outcome variable was total direct health care cost including the LTC component. In Model 2 the outcome variable was total direct health care cost excluding the LTC component. By removing the LTC facility costs, we were able to analyze the impact of pain on the remaining health care services cost.

An exchangeable correlation structure, which assumes constant correlation in successive periods for the repeated measurements was used. The model offset was the natural $\log$ of the number of person-days of follow up (the number of days in the LTC) which accounts for differences in exposure time (i.e., due to censoring). GLM model fit was evaluated using the ratio of scaled deviance to the model degrees of freedom without considering correlation; a value close to one indicates a well-fitting model. A penalized quasi-likelihood fit statistic was used to evaluate fit when the correlation structure was taken into account. Regression coefficient estimates and 95\% confidence intervals (CIs) are reported. SAS v.9.4 [45] was used to perform both the descriptive and inferential analyses.

\section{Results}

\section{Cohort characteristics}

Out of a total of 39,850 Saskatchewan LTC residents admitted between January 1, 2004 and December 31, 2015, almost two thirds $(62.4 \%, N=24,870)$ met the study inclusion criteria (Fig. 1). Of the 24,870 LTC residents, 8289 (33.3\%) were censored due to death or discharge in the 365-day study observation period. Table 1 summarizes the study cohort characteristics for the residents stratified by pain group membership at the index date. A total of 16,581 residents were observed from the admission to the end of 365-day period, of which about one third had CSP at the index date $(34.3 \%, n=5683)$ and about the same number of residents had CSP at the end of the study observation period $(33.3 \%, n=5523)$. Among those who had CSP at the baseline $(n=5683), 66.4 \%(n=$ 3773) of them also reported CSP at the end of the study observation period Residents were mainly women $(66.3 \%, n=10,896)$, residing in rural areas $(63.0 \%, n=10,443)$, with a mean age of 85.0 years
$(\mathrm{SD}=7.4)$. CSP residents were more likely to be female (71.2\%), had a higher direct health care costs one year prior to the study index date (mean = $\$ 38,815 ; \mathrm{SD}=42,868)$, and a CCI score of 3 or more (26.9\%). At the time of admission to LTC, $14.6 \%$ of residents with CSP had moderate to very severe cognitive impairment (score of $4+$ ), $10.1 \%$ had a CHESS scale of 3 to 5 and $14.5 \%$ had minimum level of functioning (ADL score of 22 to 28).

\section{Health care costs}

Table 2 summarizes the annual direct health care costs stratified by pain group. The average cost per resident was calculated separately for CSP and NP/NDMP groups by dividing the total cost by the total number of observed residents in each group. It should be noted that the death rate was similar in both groups during the 365 -day study observation period. Nearly $23 \%$ of the residents with CSP died during the study observation period versus $20 \%$ of residents with NP/NDMP.

Residents with CSP reported higher health care costs than residents with NP/NDMP (Table 2). The mean annual total direct health care cost (excluding LTC costs) per resident was $24.9 \%$ higher for the CSP group (CAD \$8063) compared to NP/NDMP group (CAD \$6455). This unadjusted difference (CAD \$1608) in cost by pain group was statistically significant $(p<0.0001)$. This pattern is consistent for each of the cost components, that is, LTC residents with CSP had higher costs for hospitalization, general and specialist physician visits, and prescription drugs. All of these cost type differences were statistically significant $(\mathrm{p}<0.0001)$. Among the CSP group, hospitalization accounted for $41.9 \%$ of the total direct health care cost (CAD \$3374/CAD \$8063) followed by prescription drugs (40.4\%), general practitioner visits (12.9\%), and specialist visits (4.9\%).

Among those with CSP at the time of admission, the top $10 \%$ of residents (in terms of costs incurred) accounted for $39.9 \%$ of the total direct health care cost (excluding LTC) and the bottom 10\% (in terms of costs incurred) residents accounted for only $1.4 \%$ of the total costs. While the NP/NDMP group also had similar percentages, the mean annual direct cost per resident (for those whose costs fell at the top $10 \%$ of the distribution) was $19.0 \%$ higher in the CSP group (CAD \$32,195 for CSP vs CAD $\$ 27,051$ for NP/NDMP). Further examination of the data broken down by cost component shows that the top $10 \%$ of residents (in terms of costs incurred) with CSP accounted for $72.1 \%$ of the total hospitalization cost and for $67.1 \%$ of the total general physician costs. Similarly, the top $10 \%$ of residents (in terms of costs incurred) with NP/NDMP accounted for $78.0 \%$ of the total hospitalization costs followed by $68.9 \%$ of the total general physician costs. Nonetheless, 
Table 1 Cohort characteristics stratified by clinically significant pain (CSP) and no pain or non-daily mild pain (NP/NDMP) at LTC admission

\begin{tabular}{|c|c|c|c|}
\hline & $\begin{array}{l}\operatorname{CSP}^{a} \\
(n=5683)\end{array}$ & $\begin{array}{l}\text { NP/NDMPa } \\
(n=10,898)\end{array}$ & $p$-value \\
\hline Age in years: Mean (SD) & $85(7.4)$ & $85(7.3)$ & 0.205 \\
\hline \multicolumn{4}{|l|}{ Age groups (years) } \\
\hline $65-74$ & $574(10.1)$ & $1089(10.0)$ & 0.835 \\
\hline $75-79$ & $690(12.1)$ & $1413(13)$ & 0.157 \\
\hline $80-84$ & $1214(21.4)$ & $2411(22.1)$ & 0.320 \\
\hline $85-89$ & $1550(27.3)$ & $2897(26.6)$ & 0.414 \\
\hline $90-94$ & $1208(21.3)$ & $2234(20.5)$ & 0.310 \\
\hline $95+$ & $447(7.9)$ & $854(7.8)$ & 0.950 \\
\hline \multicolumn{4}{|l|}{ Sex } \\
\hline Females & $4047(71.2)$ & $6939(63.7)$ & $<0.0001$ \\
\hline Males & $1636(28.8)$ & $3959(36.3)$ & $<0.0001$ \\
\hline \multicolumn{4}{|l|}{ Location of residence } \\
\hline Urban & $2111(37.2)$ & $4027(36.9)$ & 0.845 \\
\hline Rural & $3572(62.9)$ & $6871(63.1)$ & 0.881 \\
\hline \multicolumn{4}{|l|}{ Charlson comorbidity index score } \\
\hline 0 & $1551(27.3)$ & $3443(31.6)$ & $<0.0001$ \\
\hline 1 & $1576(27.7)$ & $3090(28.5)$ & 0.474 \\
\hline 2 & $1027(18.01)$ & $1929(17.7)$ & 0.591 \\
\hline $3+$ & $1529(26.9)$ & $2436(22.3)$ & $<0.001$ \\
\hline \multicolumn{4}{|l|}{ Prior health care cost $(\$)$ : } \\
\hline Mean (SD) & $38,815(42,868)$ & $32,668(42,826)$ & $<0.001$ \\
\hline Median & 25,989 & 18,798 & \\
\hline \multicolumn{4}{|l|}{ Cognitive Performance Scale (CPS) } \\
\hline Intact (score 0) & $836(14.7)$ & $1066(9.8)$ & $<0.0001$ \\
\hline Borderline intact (score 1) & $976(17.2)$ & $1343(12.3)$ & $<0.0001$ \\
\hline Mild impairment (score 2) & $1004(17.7)$ & $1879(17.2)$ & 0.533 \\
\hline Moderate (score 3) & $1605(28.2)$ & $3718(34.1)$ & $<0.0001$ \\
\hline Moderate/Severe impairment (score 4) & $216(3.8)$ & $656(6.0)$ & $<0.0001$ \\
\hline Severe impairment (score 5) & $517(9.1)$ & $1349(12.4)$ & $<0.0001$ \\
\hline Very severe impairment (score 6) & $99(1.7)$ & $173(1.6)$ & 0.416 \\
\hline Missing & $430(7.6)$ & $714(6.6)$ & 0.018 \\
\hline \multicolumn{4}{|l|}{ CHESS Scale } \\
\hline 0 & $1996(35.1)$ & $5115(46.9)$ & $<0.0001$ \\
\hline 1 & $1608(28.3)$ & $2707(24.8)$ & $<0.0001$ \\
\hline 2 & 1073 (18.9) & 1666 (15.3) & $<0.0001$ \\
\hline $3-5$ & $573(10.1)$ & $676(6.2)$ & $<0.001$ \\
\hline Missing & $433(7.6)$ & $734(6.7)$ & 0.042 \\
\hline ADL: Mean (SD) & $12.19(8.0)$ & $9.99(7.6)$ & 0.280 \\
\hline \multicolumn{4}{|l|}{ ADL categories } \\
\hline $0-7$ & 1736 (30.6) & 4562 (41.9) & $<0.0001$ \\
\hline $8-14$ & $1425(25.1)$ & 2767 (25.4) & 0.702 \\
\hline $15-21$ & $1267(22.3)$ & $1866(17.1)$ & $<0.0001$ \\
\hline $22-28$ & $825(14.5)$ & $989(9.1)$ & $<0.0001$ \\
\hline
\end{tabular}


Table 1 Cohort characteristics stratified by clinically significant pain (CSP) and no pain or non-daily mild pain (NP/NDMP) at LTC admission (Continued)

\begin{tabular}{|c|c|c|c|}
\hline & $\begin{array}{l}\operatorname{CSP}^{\mathrm{a}} \\
(n=5683)\end{array}$ & $\begin{array}{l}\text { NP/NDMP } \\
(n=10,898)\end{array}$ & $p$-value \\
\hline Missing & $430(7.8)$ & $714(6.6)$ & 0.018 \\
\hline \multicolumn{4}{|l|}{ Long term care facility type } \\
\hline Integrated & $5121(90.1)$ & 9918 (91.0) & 0.565 \\
\hline Special Care Home & $266(4.7)$ & $459(4.2)$ & 0.171 \\
\hline Hospital/Special Care Home & $296(5.2)$ & $521(4.8)$ & 0.239 \\
\hline
\end{tabular}

Note: CHESS = Changes in Health, End-stage Disease and Symptoms and Signs; ADL-Activities of Daily Living.

${ }^{\mathrm{a}}$ Frequencies (\%) are reported unless otherwise noted

pain group differences were noted for the residents who incurred the highest costs for both hospitalization (CAD $\$ 24,357$ for CSP vs CAD $\$ 20,621$ for NP/NDMP) and general physician costs (CAD \$2642 for CSP vs CAD \$ 2201) with those in the CSP group having the highest costs. A similar pattern was observed for specialist and prescription drug costs.

For those who were not discharged and did not die during the 365-day study period following LTC admission, the frequency of zero hospitalization and specialist cost was slightly higher among NP/NDMP residents (Table 3). While 78.3 and $49.4 \%$ of the NP/NDMP residents had no hospitalization or specialist cost, respectively, the corresponding percentages for CSP residents were 73.3 and $45.2 \%$ (Table 3 ). The overall distribution of total costs was bi-modal and skewed toward highercost residents, particularly for residents with CSP.

\section{Model results}

Table 4 reports the unadjusted and fully-adjusted model estimates and 95\% confidence intervals (CIs) for Model 1 and Model 2. Model 1 estimates are for cost data that include LTC costs, while Model 2 estimates are for cost data that exclude LTC costs. The ratio of the scaled deviance to the model degrees of freedom, using the gamma distribution, was close to one for both models (ratio was 1.0 in Model 1 with LTC costs and 1.2 in Model 2 without LTC costs) suggesting that both models fit the data reasonably well. The pain group $\mathrm{x}$ time interaction was statistically significant $(p<0.0001)$ in both models. The results from Model 2 (without LTC cost) were statistically significant $(p<0.0001)$ for most covariates.

The pain group $\mathrm{x}$ time interaction was positive and statistically significant in the unadjusted results (with and without including LTC costs) indicating that there were significant differences between the pain groups in cost changes over time. Even after adjusting for residents' demographic characteristics, prior direct health care costs, and facility covariates, the pain group $\mathrm{x}$ time interaction was positive and statistically significant $(p<0.0001)$ in both models. The interaction estimate indicates that the change in cost over time depends on pain status. The average cost per day was higher in the CSP group than in the NP/NDMP group.

Estimates for the main effect of time revealed a decreasing trend $(p<0.0001)$ in both models. The coefficients on other covariates were in the expected

Table 2 Mean (standard deviation) and interquartile range (IQR) of annual direct health care costs for long-term care residents with clinically significant pain (CSP) and no pain or non-daily mild pain (NP/NDMP) (CAD \$)

\begin{tabular}{|c|c|c|c|c|}
\hline Cost Component & $\begin{array}{l}\text { CSP } \\
(n=5683)\end{array}$ & $\begin{array}{l}\text { NP/NDMP } \\
(n=10,898)\end{array}$ & Difference & $P$-value \\
\hline Hospital & $\begin{array}{l}3374 \text { (9082) } \\
\text { IQR: } 1077\end{array}$ & $\begin{array}{l}2645 \text { (9330) } \\
\text { IQR: } 0^{\mathrm{a}}\end{array}$ & 729 & $<0.0001$ \\
\hline Specialist Physicians & $\begin{array}{l}394(1013) \\
\text { IQR: } 311\end{array}$ & $\begin{array}{l}319 \text { (825) } \\
\text { IQR: } 245\end{array}$ & 74 & $<0.0001$ \\
\hline General Practitioner Physicians & $\begin{array}{l}\text { 1040 (625) } \\
\text { IQR: } 920\end{array}$ & $\begin{array}{l}990(610) \\
\text { IQR: } 959\end{array}$ & 49 & $<0.0001$ \\
\hline Prescription Drug & $\begin{array}{l}3255 \text { (2419) } \\
\text { IQR: } 2535\end{array}$ & $\begin{array}{l}2500 \text { (1891) } \\
\text { IQR: } 2085\end{array}$ & 755 & $<0.0001$ \\
\hline Total, excluding LTC & $\begin{array}{l}8063(10,493) \\
\text { IQR: } 5632\end{array}$ & $\begin{array}{l}6455(10,257) \\
\text { IQR: } 3943\end{array}$ & 1608 & $<0.0001$ \\
\hline Total, including LTC & $\begin{array}{l}\text { 93,282 }(11,118) \\
\text { IQR: } 9188\end{array}$ & $\begin{array}{l}91,406(10,996) \\
\text { IQR: } 8692\end{array}$ & 1876 & $<0.0001$ \\
\hline
\end{tabular}

${ }^{\mathrm{a}}$ The IQR for NP/NDMP group is zero for hospitalization as 78\% of residents with NP/NDMP had zero hospitalization cost Note: All costs are reported in 2015 constant Canadian dollars (CAD); 
Table 3 Frequency of zero cost for long-term care residents during the 365-day study observation period following LTC admission with clinically significant pain (CSP) and no pain or non-daily mild pain (NP/NDMP)

\begin{tabular}{lll}
\hline & $\begin{array}{l}\text { CSP } \\
(\boldsymbol{n}=\mathbf{5 6 8 3})\end{array}$ & $\begin{array}{l}\text { NP/NDMP } \\
(\boldsymbol{n}=\mathbf{1 0 , 8 9 8})\end{array}$ \\
\hline Hospital & $4163(73.3 \%)$ & $8413(78.3 \%)$ \\
Specialist Physicians & $2570(45.2 \%)$ & $5382(49.4 \%)$ \\
General Physicians & $98(1.8 \%)$ & $248(2.3 \%)$ \\
Prescription Drugs & $151(2.7 \%)$ & $333(3.1 \%)$ \\
\hline
\end{tabular}

direction. Women were more likely to have a higher cost than men. Costs increased with age group. The average health care cost per day was also higher among residents who had higher cost one year prior to the LTC admission and who had a greater level of comorbidity. Residents with higher health instability (as measured by CHESS score) at the baseline had a higher average cost per day than those with no health instability (CHESS score of 0 ). Results on CPS scale suggest that residents with severe cognitive impairment (CPS score of 6) had significantly lower average cost per day than those with intact cognition (CPS score of 0). Similarly, there is a significant negative association with ADL functioning and average cost per day. The predicted mean cost without including LTC cost for the CSP group was CAD $\$ 6099$ and for the NP/NDMP group the predicted mean cost was CAD $\$ 5580$.

\section{Discussion}

To the best of our knowledge this is the first large scale investigation that estimated the cost of pain in an LTC environment by comparing direct health care costs for residents with CSP and those with NP/ NDMP. As anticipated, the mean annual health care costs for Saskatchewan LTC residents with CSP on admission (excluding LTC costs) were 25\% higher than those of NP/NDMP ( $\$ 8062.53$ vs. \$6455). Specifically, the top $10 \%$ (in terms of health care cost) residents with CSP (measured at baseline) accounted for approximately $40 \%$ of total costs, with a mean annual direct cost per person of CAD $\$ 32,195$. The results from the regression analysis further support our hypothesis that the average cost per day was higher in the CSP group than in the NP/NDMP group after controlling for various demographic characteristics, prior health care costs, measures of cognitive and physical functioning, and facility characteristics. The predicted mean cost for the group with clinically significant pain was higher than of the predicted mean cost for the NP/NDPM group. Although differences in sample population, time period, and costing methodologies make it difficult to compare with other studies, collectively our findings are in line with the literature showing that direct medical care costs are higher among patients with pain than patients without pain [12-14]. With an aging population and increasing prevalence of chronic diseases in Canada, we expect these costs to rise in the future.

Although the mean differences in cost as a function of pain status are statistically significant, our estimate of the cost of pain for older adult LTC residents is conservative for several reasons. First, our estimates only captured the direct medical care cost and did not measure the indirect cost of pain such as emotional consequences and suffering which can lower a person's quality of life. Second, the calculation of LTC cost does not consider the intensity of services required for a given resident. Third, the prescription drug database did not capture information about non-prescription drug costs.

Our pain estimates may be underestimated since the pain items of the RAI-MDS rely primarily on front line staff subjective opinion rather than systematic measurement of pain behaviors. This is particularly important in our study where we are focusing on LTC residents, some of whom are unable to report on their own pain experience due to cognitive impairment. Our results for CPS suggest that residents with severe cognitive impairment had a lower average cost per day than those whose CPS score indicate less impairment. One plausible explanation for such results could be that those with severe impairment are less likely to report pain and other symptoms due to limited communication abilities. Consequently, pain and other symptoms are less likely to be detected/recognized and, therefore, less likely to be treated, resulting in lower care costs. While we found this to be true over the one-year span of our study, it is possible that, over the longer term, undertreated pain could result in higher health care costs as health problems, with potential to increase in severity in the longer term, could go undetected in the short-term (leading to lower short term costs).

The existing literature suggests that pain in people with moderate to severe dementia can be underestimated by front line staff [46]. It is plausible that there may have been a significant portion of CSP residents who were misclassified based on the RAI-MDS. Future research should evaluate cost estimates for pain residents with severe dementia on the basis of systematic pain assessments that include well validated observational tools [47]. Moreover, the literature has documented a frequent undertreatment of pain in people with dementia and this undertreatment would have resulted in reduced health care costs. For example, several studies have indicated that patients with dementia are less likely to receive analgesics than their cognitively intact counterparts [48-50], although this may vary as a 
Table 4 Regression model estimates and 95\% confidence intervals (95\% Cls), Gamma distribution

\begin{tabular}{|c|c|c|c|c|}
\hline & \multicolumn{2}{|l|}{ Model 1} & \multicolumn{2}{|l|}{ Model 2} \\
\hline & \multicolumn{2}{|c|}{ Total cost including LTC cost } & \multicolumn{2}{|c|}{ Total cost excluding LTC cost } \\
\hline & Unadjusted & Adjusted & Unadjusted & Adjusted \\
\hline & $\begin{array}{l}\text { Estimate } \\
(95 \% \mathrm{Cl})\end{array}$ & $\begin{array}{l}\text { Estimate } \\
(95 \% \mathrm{Cl})\end{array}$ & $\begin{array}{l}\text { Estimate } \\
(95 \% \mathrm{Cl})\end{array}$ & $\begin{array}{l}\text { Estimate } \\
(95 \% \mathrm{Cl})\end{array}$ \\
\hline Intercept & $\begin{array}{l}\mathbf{5 . 6 4 9 4} \\
(5.6352,5.6637)\end{array}$ & $\begin{array}{l}5.6306 \\
(5.5945,5.6666)\end{array}$ & $\begin{array}{l}4.117 \\
(4.2073,4.2067)\end{array}$ & $\begin{array}{l}\mathbf{3 . 2 6 2 8} \\
(2.99,3.5356)\end{array}$ \\
\hline Clinically significant pain (ref: No pain/Non-daily mild pain) & $\begin{array}{l}-0.0160 \\
(-0.0341,0.0022)\end{array}$ & $\begin{array}{l}-0.0176 \\
(-0.0356,0.0003)\end{array}$ & $\begin{array}{l}-0.1983 \\
(-0.3152,0.0813)\end{array}$ & $\begin{array}{l}-0.1538 \\
(-0.2801,-0.0276)\end{array}$ \\
\hline Time & $\begin{array}{l}-0.0004 \\
(-0.0004,-0.0003)\end{array}$ & $\begin{array}{l}-0.0003 \\
(-0.0003,-0.0003)\end{array}$ & $\begin{array}{l}-0.0034 \\
(-0.0037,-0.0032)\end{array}$ & $\begin{array}{l}-0.0031 \\
(-0.0033,-0.0027)\end{array}$ \\
\hline Pain group $x$ time & $\begin{array}{l}0.0001 \\
(0.0001,0.0002)\end{array}$ & $\begin{array}{l}0.0001 \\
(0.0001,0.0002)\end{array}$ & $\begin{array}{l}\mathbf{0 . 0 0 1 4} \\
(0.001,0.0018)\end{array}$ & $\begin{array}{l}\mathbf{0 . 0 0 1 1} \\
(0.0007,0.0015)\end{array}$ \\
\hline \multicolumn{5}{|l|}{ Age (ref: 65-74) } \\
\hline 75-79 & & $\begin{array}{l}-0.0112 \\
(-0.0268,0.0043)\end{array}$ & & $\begin{array}{l}-0.0584 \\
(-0.1477,0.0308)\end{array}$ \\
\hline $80-84$ & & $\begin{array}{l}-0.0236 \\
(-0.0379,-0.0093)\end{array}$ & & $\begin{array}{l}-0.1268 \\
(-0.2103,-0.0433)\end{array}$ \\
\hline $85-89$ & & $\begin{array}{l}-0.0306 \\
(-0.0446,-0.0116)\end{array}$ & & $\begin{array}{l}-0.18 \\
(-0.2625,-0.0976)\end{array}$ \\
\hline $90-94$ & & $\begin{array}{l}-0.0362 \\
(-0.0507,-0.0217)\end{array}$ & & $\begin{array}{l}-0.2326 \\
(-0.3299,-0.1423)\end{array}$ \\
\hline $95+$ & & $\begin{array}{l}-0.0585 \\
(-0.0734,-0.0436)\end{array}$ & & $\begin{array}{l}-0.441 \\
(-0.5466,-0.3416)\end{array}$ \\
\hline $\begin{array}{l}\text { Sex: (ref: female) } \\
\text { Male }\end{array}$ & & $\begin{array}{l}0.0052 \\
(0.0008,0.0112)\end{array}$ & & $\begin{array}{l}\mathbf{0 . 0 8 9 8} \\
(0.0452,0.1344)\end{array}$ \\
\hline $\begin{array}{l}\text { Location of residence (ref: Urban) } \\
\text { Rural }\end{array}$ & & $\begin{array}{l}-0.0043 \\
(-0.0098,0.0012)\end{array}$ & & $\begin{array}{l}-0.0507 \\
(-0.0953,0.0061)\end{array}$ \\
\hline \multicolumn{5}{|l|}{ Charlson comorbidity index score (ref: $3+$ ) } \\
\hline 0 & & $\begin{array}{l}-0.0103 \\
(-0.0155,-0.0051)\end{array}$ & & $\begin{array}{l}-0.0336 \\
(-0.0785,0.0114)\end{array}$ \\
\hline 1 & & $-0.01(-0.0146,-0.0054)$ & & $\begin{array}{l}-0.0683 \\
(-0.1052,-0.0315)\end{array}$ \\
\hline 2 & & $\begin{array}{l}-0.0005 \\
(-0.0062,0.0053)\end{array}$ & & $\begin{array}{l}-0.0103 \\
(-0.0503,0.0296)\end{array}$ \\
\hline Prior health care cost & & $\begin{array}{l}\mathbf{0 . 0 0 4 7} \\
(0.0019,0.0074)\end{array}$ & & $\begin{array}{l}\mathbf{0 . 0 9 7 8} \\
(0.0772,0.1183)\end{array}$ \\
\hline \multicolumn{5}{|l|}{ Cognitive Performance Scale (CPS) (ref: 0) } \\
\hline 1 & & $\begin{array}{l}-0.0079 \\
(-0.0207,0.005)\end{array}$ & & $\begin{array}{l}-0.0814 \\
(-0.1684,0.0057)\end{array}$ \\
\hline 2 & & $\begin{array}{l}-\mathbf{0 . 0 2 6} \\
(-0.0376,-0.0144)\end{array}$ & & $\begin{array}{l}-0.1716 \\
(-0.2557,-0.0876)\end{array}$ \\
\hline 3 & & $\begin{array}{l}-0.0273 \\
(-0.0389,-0.0157)\end{array}$ & & $\begin{array}{l}-0.233 \\
(-0.3141,-0.1519)\end{array}$ \\
\hline 4 & & $\begin{array}{l}-\mathbf{0 . 0 2 7 7} \\
(-0.0429,-0.0125)\end{array}$ & & $\begin{array}{l}-0.1946 \\
(-0.3153,-0.0739)\end{array}$ \\
\hline 5 & & $\begin{array}{l}-0.0246 \\
(-0.0375,-0.0118)\end{array}$ & & $\begin{array}{l}-0.232 \\
(-0.3253,-0.1388)\end{array}$ \\
\hline 6 & & $\begin{array}{l}-0.0388 \\
(-0.0552,-0.0225)\end{array}$ & & $\begin{array}{l}-0.3097 \\
(-0.4444,-0.175)\end{array}$ \\
\hline \multicolumn{5}{|l|}{ Activities of Daily Living (ADL): (ref: 0-7) } \\
\hline $8-14$ & & $\begin{array}{l}-0.0025 \\
(-0.0105,0.0055)\end{array}$ & & $\begin{array}{l}-0.0039 \\
(-0.0641,0.0562)\end{array}$ \\
\hline
\end{tabular}


Table 4 Regression model estimates and 95\% confidence intervals (95\% Cls), Gamma distribution (Continued)

\begin{tabular}{|c|c|c|c|c|}
\hline & \multicolumn{2}{|l|}{ Model 1} & \multicolumn{2}{|l|}{ Model 2} \\
\hline & \multicolumn{2}{|c|}{ Total cost including LTC cost } & \multicolumn{2}{|c|}{ Total cost excluding LTC cost } \\
\hline & Unadjusted & Adjusted & Unadjusted & Adjusted \\
\hline & $\begin{array}{l}\text { Estimate } \\
(95 \% \mathrm{Cl})\end{array}$ & $\begin{array}{l}\text { Estimate } \\
(95 \% \mathrm{Cl})\end{array}$ & $\begin{array}{l}\text { Estimate } \\
(95 \% \mathrm{Cl})\end{array}$ & $\begin{array}{l}\text { Estimate } \\
(95 \% \mathrm{Cl})\end{array}$ \\
\hline $15-21$ & & $\begin{array}{l}-0.0116 \\
(-0.0191,-0.004)\end{array}$ & & $\begin{array}{l}-0.0923 \\
(-0.1509,-0.0338)\end{array}$ \\
\hline $22-28$ & & $\begin{array}{l}-0.0115 \\
(-0.021,-0.0021)\end{array}$ & & $\begin{array}{l}-0.1043 \\
(-0.1733,-0.0353)\end{array}$ \\
\hline \multicolumn{5}{|c|}{ Changes in Health, End-Stage Disease and Signs and Symptoms (CHESS) (ref: 0) } \\
\hline 1 & & $\begin{array}{l}\mathbf{0 . 0 1 0 9} \\
(0.0037,0.0181)\end{array}$ & & $\begin{array}{l}\mathbf{0 . 0 8 0 6} \\
(0.0261,0.1352)\end{array}$ \\
\hline 2 & & $\begin{array}{l}\mathbf{0 . 0 1 1 5} \\
(0.0042,0.0188)\end{array}$ & & $\begin{array}{l}\mathbf{0 . 0 8 8 2} \\
(0.0333,0.1431\end{array}$ \\
\hline $3-5$ & & $\begin{array}{l}\mathbf{0 . 0 1 7} \\
(0.0075,0.0265)\end{array}$ & & $\begin{array}{l}\mathbf{0 . 1 2 4 9} \\
(0.0559,0.194)\end{array}$ \\
\hline \multicolumn{5}{|c|}{ Long term care facility type (ref: Integrated) } \\
\hline Special care homes & & $\begin{array}{l}\mathbf{0 . 0 6 8 7} \\
(0.0378,0.0996)\end{array}$ & & $\begin{array}{l}\mathbf{0 . 4 4 2 5} \\
(0.2966,0.6253)\end{array}$ \\
\hline Hospital/Special Care home & & $\begin{array}{l}-0.0071 \\
(-0.0182,0.004)\end{array}$ & & $\begin{array}{l}-0.0324 \\
(-0.1306,0.0658)\end{array}$ \\
\hline
\end{tabular}

Note: Bold values indicate statistically significant at $\mathrm{a}=0.05$

function of setting. Attitudinal barriers to effective pain assessment and management in dementia continue to exist [51].

In summary, pain in LTC increases health care costs substantially. Improved pain assessment and management have the potential of reducing such costs and improving life quality for residents. We also believe that the identified cost difference between residents with CSP and those with NP/NDMP is likely underestimated due to the strong possibility that pain problems are often missed among many residents with severe dementia and limited ability to communicate verbally. Future longitudinal clinical research, involving frequent and systematic pain assessments of residents, could potentially provide more accurate estimates of cost difference than we were able to obtain from administrative databases.

\section{Study limitations}

In this study, we classified residents based on pain status as determined by the RAI-MDS pain scale. Although this scale has been validated against resident self-report [34], conclusions are based on nurse opinion and may not be as valid for residents who cannot self-report pain due to aphasia or severe cognitive impairment. Moreover, given that the scale relies heavily on clinician opinion rather than objective pain indicators, we did not feel that it has sufficient sensitivity to identify fine gradations in pain experience. As a result we used an approach that classified the patients into two pain status groups (CSP and
NP/NDMP). As such, our analysis does not allow us to evaluate whether there is a direct dose-response relationship between amount of pain experienced and costs. This may be possible to determine in future research that involves other types of pain indices that may be able to reflect accurately gradations in the pain experience [52].

Finally, some variables that may be relevant to cost determination (e.g., facility size, owner/operator model) were not available in our data set. Given that a large proportion of Saskatchewan residents live in rural areas, our results may not generalize to all LTC populations in Canada. A wide body of evidence [53] suggests significant disparities in the health status and quality of care received between rural and urban populations. Future research should extend our work using national-level data to understand any inter-regional variations in the cost of care for pain residents.

\section{Conclusion}

Clinically significant pain in LTC is associated with greater health care costs. Related to this, research has demonstrated that there are significant knowledge gaps among LTC and other health professional staff when it comes to pain assessment and management [54, 55]. The policy implications of our findings are clear: As has been suggested by others [56], allocation of resources of for pain education and development of mandated minimum standards for improved pain assessment and management in LTC are necessary, not only for the quality 
of life of residents, but also for potential long-term cost savings. Earlier pain detection and treatment may result in future cost savings. Although in this investigation we were not able to consider the impact of pain treatment on health care spending, as demonstrated, outside LTC environments [57], early and effective identification and treatment of pain may result in substantial cost savings, improved quality of life, and prevention of health deterioration. With the rising cost of health care and limited health care budgets, the impact of such treatments in LTC environments merits further study.

\begin{abstract}
Abbreviations
CANSIM: Canadian Socio-Economic Information Management System; CMG: Case-Mix Groups; CCl: Charlson comorbidity index; CSP: Clinically significant pain; Cls: Confidence intervals; CPI: Consumer Price Index; DAD: Discharge Abstract Database; DIN: Drug identification number; GEEs: Generalized estimating equations; GLMs: Generalized linear models; ICD-9: International Classification of Diseases, 9th revision, Canadian enhancement codes; ICD-10-CA: International Classification of Diseases, 10th revision, Canadian enhancement codes; ISCH: Institutional Supportive Care Home; IQR: Interquartile range; LTC: Long-term care; NP: No pain; NDMP: Non-daily mild pain; PHRS: Person Health Registry System; RAIMDS: Resident Assessment Instrument-Minimum Data Set; RIW: Resource Intensity Weight; SCHS: Special Care Home System; SD: Standard deviations
\end{abstract}

\section{Supplementary Information}

The online version contains supplementary material available at https://doi. org/10.1186/s12877-021-02424-2.

Additional file 1: Supplementary Table 1. Baseline pain frequency and intensity stratified by sex.

\section{Acknowledgements}

The authors thank Jacqueline Quail, Nedeene Hudema and Nianping Hu for their assistance with this project. This research was supported through funding from the Canadian Institutes of Health Research and the Saskatchewan Health Research Foundation.

\section{Authors' contributions}

Harminder Guliani and Lisa Lix designed the study, oversaw the statistical analysis, and interpreted the study results. Shan Jin conducted the statistical analysis. Harminder Guliani made major contributions to the preparation of the manuscript with input from all authors. Thomas Hadjistavropoulos prepared the grants that funded this work, and contributed to the formulation of the research questions, preparation of the manuscript and interpretation of the results. All authors edited and approved the final manuscript.

\section{Funding}

This work was supported through funding from the Canadian Institutes of Health Research (grant \# CIHR-SPOR-CPN) and the Saskatchewan Health Research Foundation (grant \# 2908).

\section{Availability of data and materials}

The data that support the findings of the study are available from the Health Quality Council of Saskatchewan but restrictions apply to the availability of these data, which were used under contract for the current study, and so are not publically available. Researchers may access the data by forming a partnership with the Saskatchewan Health Quality Council as indicated on their website: https://www.hqc.sk.ca/research-partnerships/other-researchpartnerships.

\section{Declarations}

\section{Ethics approval and consent to participate}

This research was approved by the Research Ethics Board (approval number 2017-65), University of Regina and involved Saskatchewan Health Quality Council data bases. All procedures of the study were conducted in accordance with the Declaration of Helsinki. The research is based on deidentified population health data collected routinely by the Government of Saskatchewan. As such, consent for participation in/withdrawal from the study are not applicable as determined by the University of Regina Research Ethics Board.

\section{Consent for publication}

The manuscript does not contain any individual person's data in any form.

\section{Competing interests}

No authors of this study have personal, professional or financial conflicts to declare.

\section{Author details}

${ }^{1}$ Department of Economics, University of Regina, 3737 Wascana Pkwy, Regina, SK S4S OA2, Canada. 'Department of Psychology and Centre on Aging and Health, University of Regina, 3737 Wascana Pkwy, Regina, SK S4S 0A2, Canada. ${ }^{3}$ Saskatchewan Health Quality Council, 241 - 111 Research Drive Saskatoon, Saskatoon, SK 7N 3R2, Canada. ${ }^{4}$ Department of Community Health Sciences, University of Manitoba, S113-750 Bannatyne Ave, Winnipeg, MB R3E OW3, Canada.

Received: 3 February 2021 Accepted: 26 August 2021

Published online: 14 October 2021

\section{References}

1. Russell TL, Madsen RW, Flesner M, Rantz MJ. Pain management in nursing homes: what do quality measure scores tell us? J Gerontol Nurs. 2010; 36(12):49-56. https://doi.org/10.3928/00989134-20100504-07.

2. Won AB, Lapane KL, Vallow S, Schein J, Morris JN, Lipsitz LA. Persistent nonmalignant pain and analgesic prescribing patterns in elderly nursing home residents. J Am Geriatr Soc. 2004;52(6):867-74. https://doi.org/1 0.1111/j.1532-5415.2004.52251.x.

3. Louro M, Matos A, Leitão S, Santos R, Carvalho A. Pain management in patients with advanced dementia: a Portuguese study. Int J Innov Stud Med Sci. 2018;2(1):4-7. ISSN 2457-063X (Online).

4. Bauer U, Pitzer S, Schreier MM, Osterbrink J, Alzner R, Iglseder B. Pain treatment for nursing home residents differs according to cognitive state a cross-sectional study. BMC Geriatr. 2016;16(1):124. https://doi.org/10.1186/ s12877-016-0295-1.

5. Hadjistavropoulos T, Herr K, Prkachin KM, Craig KD, Gibson SJ, Lukas A, et al. Pain assessment in elderly adults with dementia. Lancet Neurol. 2014;13(12): 1216-27. https://doi.org/10.1016/S1474-4422(14)70103-6.

6. Fuchs-Lacelle S, Hadjistavropoulos T, Lix L. Pain assessment as intervention: a study of older adults with severe dementia. Clin J Pain. 2008;24(8):697707. https://doi.org/10.1097/AJP.0b013e318172625a.

7. Hadjistavropoulos T, Kaasalainen S, Williams J, Zacharias R. Improving pain assessment practices and outcomes in long-term care facilities: a mixed methods investigation. Pain Manag Nurs. 2014;15(4):748-59. https://doi. org/10.1016/j.pmn.2013.07.009.

8. Gagnon MM, Hadjistavropoulos T, Williams J. Development and mixedmethods evaluation of a pain assessment video training program for longterm care staff. Pain Res Manag. 2013;18(6):307-12. https://doi.org/10.1155/2 013/659320.

9. Lynch ME. The need for a Canadian pain strategy. Pain Res Manag. 2011; 16(2):77-80. https://doi.org/10.1155/2011/654651.

10. Phillips CJ, Schopflocher D. The Economics of Chronic Pain. In: Rashiq S, Schopflocher D, Taenzer P, Jonsson E, editors. Chronic Pain: A Health Policy Perspective. [Internet]. 1st ed. Wienheim: Wiley; 2008:41-50. [cited 2021 Jul 12]. Available from: https://onlinelibrary.wiley.com/doi/10.1002/9783527622 665.ch4 .

11. Guerriere DN, Choinière M, Dion D, Peng P, Stafford-Coyte E, Zagorski B, et al. The Canadian STOP-PAIN project - part 2: what is the cost of pain for patients on waitlists of multidisciplinary pain treatment facilities? Can J 
Anesth Can Anesth. 2010;57(6):549-58. https://doi.org/10.1007/s12630-0109306-4.

12. Hogan M-E, Taddio A, Katz J, Shah V, Krahn M. Incremental health care costs for chronic pain in Ontario, Canada: a population-based matched cohort study of adolescents and adults using administrative data. Pain. 2016;157(8): 1626-33. https://doi.org/10.1097/j.pain.0000000000000561.

13. Lalonde L, Martin E, Berbiche D, Perreault S, Lussier D, Choiniere M. Costs of moderate to severe chronic pain in primary care patients \&ndash; a study of the ACCORD program. J Pain Res. 2014;389:389-404.

14. Gaskin DJ, Richard P. The economic costs of pain in the United States. J Pain. 2012;13(8):715-24. https://doi.org/10.1016/j.jpain.2012.03.009.

15. Access Economics. Painful realities: the economic impact of arthritis in Australia in 2007. Canberra: Arthritis Australia; 2007.

16. Langley PC. The societal burden of pain in Germany: Health-related qualityof-life, health status and direct medical costs. J Med Econ. 2012;15(6):120115. https://doi.org/10.3111/13696998.2012.716383.

17. Raftery MN, Ryan P, Normand C, Murphy AW, de la Harpe D, McGuire BE. The economic cost of chronic noncancer pain in Ireland: results from the PRIME study, part 2. J Pain. 2012;13(2):139-45. https://doi.org/10.1016/j.jpa in.2011.10.004

18. Guliani H, Hadjistavropoulos T, Jin S, Lix L. Utilization of health care resources by long-term care residents as a function of pain status. Clin J Pain. 2020;36(6):472-9. https://doi.org/10.1097/AJP.0000000000000826.

19. Statistics Canada. Focus on Geography Series, 2016 Census. [Internet]. 2016 [cited 2020 Mar 1]. Available from: https://www12.statcan.gc.ca/censusrecensement/2016/as-sa/fogs-spg/Facts-can-eng.cfm?Lang=Eng\&GK=CA $\mathrm{N} \& \mathrm{GC}=01 \& \mathrm{TOPIC}=7$

20. Moffat D. RAI-MDS Overview in long-term care [Internet]. 2010 [cited 2017 Jan 15]. Available from: www.centrallhin.on.ca. Accessed 15 Jan 2015.

21. Canadian Institute of Health Information. Continuing care reporting system data users' guide [Internet]. 2017 [cited 2020 May 5]. Available from: https:// secure.cihi.ca/free_products/CCRS-external-data-users-guide-2017-2018-enweb.pdf. Accessed 5 May 2020.

22. Canadian Institute of Health Information. Codes and classifications [Internet]. 2020 [cited 2020 Feb 18]. Available from: https://www.cihi.ca/en/submit-da ta-and-view-standards/codes-and-classifications. Accessed 18 Feb 2020.

23. Canadian Institute of Health Information. ICD-9/CCP and ICD-9-CM [Internet]. 2020 [cited 2020 Feb 8]. Available from: https:/www.cihi.ca/en/submit-data-a nd-view-standards/icd-9ccp-and-icd-9-cm. Accessed 8 Feb 2020.

24. Lix LM, Yan L, Blackburn D, Hu N, Schneider-Lindner V, Shevchuk Y, et al. Agreement between administrative data and the resident assessment instrument minimum dataset (RAI-MDS) for medication use in long-term care facilities: a population-based study. BMC Geriatr. 2015;15(1):24. https:// doi.org/10.1186/s12877-015-0023-2.

25. Lix LM, Kuwornu JP, Kroeker K, Kephart G, Sikdar KC, Smith M, et al. Estimating the completeness of physician billing claims for diabetes case ascertainment using population-based prescription drug data. Health Promot Chronic Dis Prev Can Res Policy Pract. 2016;36(3):54-60.

26. Statistics Canada. Consumer Price Index, annual average, not seasonally adjusted [Internet]. Government of Canada; [cited 2021 Jul 12]. Available from: https://www150.statcan.gc.ca/t1/tbl1/en/tv.action?pid=1810000501

27. Manitoba Centre for Health Policy (MCHP). Concept: Costing methods: An overview of costing health services in Manitoba [Internet]. 2017 [cited 2020 Sep 1]. Available from: http://mchp-appserv.cpe.umanitoba.ca/viewConcept. php?printer $=$ Y\&conceptID $=1354$

28. Wodchis WP, Bushmeneva K, Nikitovic M, McKillop I. Guidelines on person-level costing using administrative databases in Ontario. Toronto: Toronto: Health System Performance Research Network; 2013. (Working Paper Series Vol. 1)

29. Canadian Institute of Health Information. Cost of a standard hospital stay: appendices to Indicator library — methodology notes, may 2020. Ottawa: $\mathrm{CIHI} ; 2020$.

30. Pink GH, Bolley HB. Physicians in health care management: 3. Case mix groups and tesource intensity weights: an overview for physicians. CMAJ Can Med Assoc J J Assoc Medicale Can. 1994;150(6):889-94.

31. CIHI. Case mix tools: Case mix tools for decision making in health care [Internet]. [cited 2020 Sep 1]. Available from: https://www.cihi.ca/en/ submit-data-and-view-standards/methodologies-and-decision-supporttools/case-mix

32. Cunningham C, Cai P, Topps D, Svenson LW, Jetté N, Quan H. Mining rich health data from Canadian physician claims: features and face validity. BMC Res Notes. 2014;7(1):682. https://doi.org/10.1186/1756-0500-7-682.
33. Armstrong H, Daly TJ, Choiniere JA. Policies and practices: the case of RAlMDS in Canadian long-term care homes. J Can Stud. 2017:50(2):348-67. https://doi.org/10.3138/jcs.50.2.348.

34. Fries BE, Simon SE, Morris JN, Flodstrom C, Bookstein FL. Pain in U.S. nursing homes: validating a pain scale for the minimum data set. Gerontologist. 2001;41(2):173-9. https://doi.org/10.1093/geront/41.2.173.

35. Alberta Health. RAI-MDS 2.0 quality indicator interpretation guide [internet]. In: . Edmonton, AB: Government of Alberta; Available from: https:/open.a Iberta.ca/dataset/aa056894-c85f-4526-a3da-25cd64795082/resource/ 05bfbf33-070c-49d7-a4ce-1fc7857741cd/download/cc-cihi-rai-guide-2015. pdf. Accessed 20 June 2021

36. Canadian Institute of Health Information. Describing outcome scales (RAIHC) [Internet]. CIHI; 2013. Available from: : https://www.cihi.ca/sites/default/ files/document/outcome_scales_rai-hc_en.pdf. Accessed 31 Aug 2021.

37. Morris JN, Fries BE, Morris SA. Scaling ADLs within the MDS. J Gerontol A Biol Sci Med Sci. 1999;54(11):M546-53. https://doi.org/10.1093/gerona/54.11. M546.

38. Hirdes JP, Frijters DH, Teare GF. The MDS-CHESS scale: a new measure to predict mortality in institutionalized older people. J Am Geriatr Soc. 2003; 51(1):96-100. https://doi.org/10.1034/j.1601-5215.2002.51017.x.

39. Charlson ME, Pompei P, Ales KL, Mackenzie CR. A new method of classifying prognostic comorbidity in longitudinal studies: development and validation. J Chronic Dis. 1987;40(5):373-83. https://doi.org/10.1016/0021-9681(87)90171-8.

40. Klabunde CN, Potosky AL, Legler JM, Warren JL. Development of a comorbidity index using physician claims data. J Clin Epidemiol. 2000;53(12): 1258-67. https://doi.org/10.1016/S0895-4356(00)00256-0.

41. Quan H, Sundararajan V, Halfon P, Fong A, Burnand B, Luthi J, et al. Coding algorithms for defining comorbidities in ICD-9-CM and ICD-10 administrative data. Med Care. 2005;43(11):1130-9. https://doi.org/10.1097/ 01.mlr.0000182534.19832.83.

42. Government of Saskatchewan. Institutional supportive care homes information system manual guideline/General Information [Internet]. [cited 2020 Sep 1]. Available from: https://pubsaskdev.blob.core.windows.net/ pubsask-prod/98649/98649-Program_Guidelines_2016.pdf.

43. Manning WG, Basu A, Mullahy J. Generalized modeling approaches to risk adjustment of skewed outcomes data. J Health Econ. 2005;24(3):465-88. https://doi.org/10.1016/j.jhealeco.2004.09.011.

44. Mihaylova B, Briggs A, O'Hagan A, Thompson SG. Review of statistical methods for analysing healthcare resources and costs. Health Econ. 2011; 20(8):897-916. https://doi.org/10.1002/hec.1653.

45. SAS Institute Inc. SAS [computer program]. Cary: SAS Institute Inc.; 2011.

46. Marzinski LR. The tragedy of dementia: clinically assessing pain in the confused, nonverbal elderly. J Gerontol Nurs. 1991;17(6):25-8. https://doi. org/10.3928/0098-9134-19910601-08.

47. Herr K, Coyne PJ, Ely E, Gélinas C, Manworren RCB. ASPMN 2019 position statement: pain assessment in the patient unable to self-report. Pain Manag Nurs. 2019;20(5):402-3. https://doi.org/10.1016/j.pmn.2019.07.007.

48. Balfour JE, O'Rourke N. Older adults with Alzheimer's disease, comorbid arthritis and prescription of psychotropic medications. Pain Res Manag. 2003;8(4):198-204. https://doi.org/10.1155/2003/105459.

49. Hemmingsson E-S, Gustafsson M, Isaksson U, Karlsson S, Gustafson Y, Sandman P-O, et al. Prevalence of pain and pharmacological pain treatment among old people in nursing homes in 2007 and 2013. Eur J Clin Pharmacol. 2018;74(4):483-8. https://doi.org/10.1007/s00228-017-2384-2.

50. Nygaard HA, Jarland M. Are nursing home patients with dementia diagnosis at increased risk for inadequate pain treatment? Int J Geriatr Psychiatry. 2005;20(8):730-7. https://doi.org/10.1002/gps.1350.

51. Chandler R, Zwakhalen S, Docking R, Bruneau B, Bruneau P. Attitudinal and knowledge barriers towards effective pain assessment \& management in dementia: a narrative synthesis. Curr Alzheimer Res. 2017;14(5):523-37. https://doi.org/10.2174/1567205013666160602233118.

52. Lints-Martindale AC, Hadjistavropoulos T, Barber B, Gibson SJ. A psychophysical investigation of the facial action coding system as an index of pain variability among older adults with and without Alzheimer's disease. Pain Med. 2007;8(8):678-89. https://doi.org/10.1111/j.1526-4637.2007.00358.x.

53. Coburn AF. Rural elders and long-term care. West J Med. 2001;174(3):20913. https://doi.org/10.1136/ewjm.174.3.209.

54. Watt-Watson J, McGillion M, Hunter J, Choiniere M, Clark A, Dewar A, et al. A survey of prelicensure pain curricula in health science faculties in Canadian universities. Pain Res Manag. 2009;14(6):439-44. https://doi.org/1 $0.1155 / 2009 / 307932$. 
55. Zwakhalen SM, Hamers JP, Peijnenburg RH, Berger MP. Nursing staff knowledge and beliefs about pain in elderly nursing home residents with dementia. Pain Res Manag. 2007;12(3):177-84. https://doi.org/10.1155/2007/ 518484.

56. Gallant NL, Peckham A, Marchildon G, Hadjistavropoulos T, Roblin B, Stopyn RJN. Provincial legislative and regulatory standards for pain assessment and management in long-term care homes: a scoping review and in-depth case analysis. BMC Geriatr. 2020;20(1):458. https://doi.org/10.1186/s12877-020-01 758-7.

57. Sletten CD, Kurklinsky S, Chinburapa V, Ghazi S. Economic analysis of a comprehensive pain rehabilitation program: a collaboration between Florida blue and Mayo Clinic Florida. Pain Med. 2015;16(5):898-904. https://doi. org/10.1111/pme.12679.

\section{Publisher's Note}

Springer Nature remains neutral with regard to jurisdictional claims in published maps and institutional affiliations.

Ready to submit your research? Choose BMC and benefit from:

- fast, convenient online submission

- thorough peer review by experienced researchers in your field

- rapid publication on acceptance

- support for research data, including large and complex data types

- gold Open Access which fosters wider collaboration and increased citations

- maximum visibility for your research: over $100 \mathrm{M}$ website views per year

At BMC, research is always in progress.

Learn more biomedcentral.com/submissions 